\title{
Prevalence and Risk Factors for Hypovitaminosis D among Healthy Adolescents in Kota Bharu, Kelantan
}

\author{
Suhaimi Hussain and Maged Elnajeh \\ Hospital University Science Malaysia
}

\begin{abstract}
Objective. We aim to study the prevalence and risk factors of hypovitaminosis D among healthy adolescents in Kota Bharu, Kelantan based on the most recent Paediatric Consensus guideline.

Methodology. Ten public schools were selected from Kota Bharu, Kelantan. We analysed their demography (age, gender, ethnicity, income), measured their anthropometry (height, weight, BMI) and finally analysed their vitamin D and intactParathyroid hormone levels.

Results. The prevalence of hypovitaminosis D was $16.9 \%$ among healthy teenagers with mean age of $15.9 \pm 1.39$ years Multivariate analysis showed female gender (adjusted OR, 95\% CI): $23.7(5.64,100.3)$ and Chinese $0.24(0.07,0.84)$ were the significant predictors for hypovitaminosis $D$.

Conclusion. The prevalence of healthy adolescents with hypovitaminosis D in Kota Bharu, Kelantan was $16.9 \%$ using the most recent cut off value of $30 \mathrm{nmol} / \mathrm{L}$ from the global consensus 2016. Female and Malay were the significant risk factors associated with hypovitaminosis D. Higher cut off value would result in overestimation of prevalence rate of hypovitaminosis D.
\end{abstract}

Key words: hypovitaminosis $D$, adolescents, nutritional rickets

\section{INTRODUCTION}

Hypovitaminosis D or vitamin D deficiency is a cause of nutritional rickets. Rickets is due to defective bone mineralization in growing children. Vitamin D plays a major role in calcium regulation and as calcium is the main mineral in the bones, deficiency of vitamin D would lead to failure to absorb calcium and therefore it results in poor bone mineralization or rickets. ${ }^{1-4}$ Vitamin $\mathrm{D}$ deficiency during teenage years compromise bone mass and put teenagers at risk of adverse consequences of skeletal health; and there is also increase in likelihood of other medical problems in the future such as diabetes, hypertension, metabolic syndrome and certain cancers such as colorectal cancer. ${ }^{5-7}$ The prevalence of vitamin D deficiency worldwide varies widely depending on the definition used in the trials. It can be as low as $0.4 \%$ in China and as high as $86 \%$ in Middle East if it is based on the definition of vitamin D level $<30 \mathrm{nmol} / \mathrm{L}$. With higher cut off used, the reported prevalence ranged from 5-99\%. ${ }^{8-10}$ Global consensus 2016 recommendations on prevention and management of nutritional rickets has defined vitamin D deficiency using $<30 \mathrm{nmol} / \mathrm{L}$ as the critical cut off below which nutritional rickets is more likely to occur. ${ }^{11}$ This definition is consistent with that of The Institute of Medicine (IOM). ${ }^{12}$ Malaysian Health and Adolescents Longitudinal Research Team Study (MyHeARTs) reported the prevalence of vitamin D deficiency was 33\% among adolescents with mean age of 15 years old from Selangor, Perak and the capital of Malaysia, Kuala Lumpur. However, the definition was based on higher cut off or adult value of $50 \mathrm{nmol} / \mathrm{L} .{ }^{13}$

Eighty percent of the source of vitamin D is from skin synthesis following exposure to sun light. UVB from the sunlight would convert 7-dehydrocholesterol in the skin to cholecalciferol which will later be hydroxylated to inactive vitamin $\mathrm{D}$ in the liver then active vitamin $\mathrm{D}$ in the kidney. Any factors that may interfere with skin synthesis related to sociodemographic factors would lead to vitamin D deficiency. ${ }^{14-16}$ Any diseases that would affect liver, kidney and gut would also impair synthesis of vitamin $\mathrm{D}$ since liver and kidney are involved in the steps for hydroxylation of vitamin D while gut is the site at which active vitamin $\mathrm{D}$ and parathyroid hormone act to increase calcium and oral vitamin D absorption from the food. Known risk factors associated with vitamin D deficiency are poor sunlight exposure, sunscreen usage, darker skin, poor diet, older age, clothing, obesity, female gender and geographical location away from equator. ${ }^{17-33}$ The purpose of this trial was to investigate the prevalence of vitamin D deficiency using the most recent definition from the 2016 Global consensus in Kelantan which is one of the poorest states in Malaysia, and to study factors associated with vitamin $\mathrm{D}$ deficiency. Healthy adolescents were selected 
as teenage years is marked by the highest bone mineral accrual and if they do not have the optimal storage of vitamin $\mathrm{D}$, they are more likely to face all detrimental effects of hypovitaminosis D as an adult. ${ }^{34}$

\section{METHODOLOGY}

\section{Sampling design}

There were 45 public secondary schools in Kota Bharu based on the list provided by the Kelantan State Education. It was decided that ten schools were sufficient in order to recruit the required sample size. Participants were selected via nonprobability sampling. Specifically, students were recruited via purposive sampling. With the assistance and supervision of the teachers in charge, an invitation to participate were given to students in class who met the inclusion criteria. The students who expressed their interest were invited for a briefing by the primary research team.

\section{Research tool}

Subjects who gave consent, were asked to fill in the questionnaire to explore about sociodemographic factors. Height and weight were measured using standardized instruments and methods. Blood for 25-(OH)Vit D, intact-PTH were taken in EDTA tubes, centrifuged and stored at -80 degree centigrade. Vitamin D was analysed using Elecsys Vitamin D Cobas that utilised Electro Chemiluminescent Immunoassay for the quantitative measurement of total vitamin D. The Elecsys Vitamin D demonstrated good overall performance with a precision testing that showed within-run coefficient of variations (CVs) of $<7 \%$, within-laboratory CVs of $9.5 \%$, betweenlaboratory precision $\mathrm{CVs}$ of $<10.1 \%$ and a functional sensitivity below $9.8 \mathrm{nmol} / \mathrm{L}$ (at CV 12.9\%).

\section{Inclusion and exclusion}

Healthy adolescents with age from 13-18 years old, without major medical problems such as kidney, liver and gut diseases were included. The information with regard to the health status and intake of vitamin D supplements were answered by parents in the questionnaire. Those who were on vitamin D supplements and had incomplete data entry were excluded.

\section{Statistical analysis}

Data analysis was performed using SPSS (IBM) version 22. Numerical data (age, weight, height, vitamin D, I-PTH) were expressed as mean and standard deviation while categorical data (gender, race, BMI) were presented as number and percentage. Simple and multiple logistic regression were applied to study the factors that affect vitamin D deficiency.

The prevalence of vitamin D deficiency was determined using a single proportion formula at confidence level/z $=95 \%$ or 1.96 , margin of error at $5 \% /$ standard value of 0.05 and an estimated prevalence from Perez-Lopez et al., Jan $2010=28 \%$. By using the formula, a sample of 310 subjects was required to obtain a $95 \%$ confidence interval of $5 \%$ around a prevalence estimate of $20 \%$ and in order to allow for an expected $20 \%$ drop out rate (62), a total of 372 students were needed. Sample size for calculating factors associated with hypovitaminosis D was calculated with Pocock's formula for comparing two proportions. Both numerical and categorical data were selected for the analysis of factors associated with hypovitaminosis D in the binary logistic regression with hypovitaminosis D as the dependent variable or outcome. From the results of simple logistic regression, selected variables / independent variables that have $p$ value $<0.25$ were included in the multiple logistic regression. As for the multiple logistic regression analysis, we used forward and backward LR initially and it was decided to use the output of backward LR for the presentation of the final results.

\section{Ethical Approval}

The study was approved by the University Ethical Board with its reference USM/PPP/Ethics Com. /2012(60)

\section{RESULTS}

A total of 361 healthy adolescents with the mean age (SD); $15.9 \pm 1.39$ years, age range (13-18 years) were recruited from 10 public schools in Kota Bharu, Kelantan. The predominant race was Malay, 307 (85\%) while 54 (15\%) were Chinese students. Female subjects outnumbered male with $227(62.9 \%)$ vs $134(37.1 \%)$. The mean vitamin D level was $19.62 \mathrm{ng} / \mathrm{mL}$, 95\% CI $(18.77,20.47)$ with interval estimates $19.62 \pm 0.8466$. The average vitamin D level lies between 18.7 and $20.46 \mathrm{ng} / \mathrm{mL}$. The prevalence of hypovitaminosis D / vitamin D deficiency based on the definition of $<30 \mathrm{nmol} / \mathrm{L}$ or $12 \mathrm{ng} / \mathrm{mL}$ was $16.3 \%$. The mean weight and height (SD) were $53.0 \pm 16.8 \mathrm{~kg}, 156.2 \pm 19.2 \mathrm{~cm}$. The mean (SD) of vitamin D level and intact-PTH were $19.6 \pm 8.2 \mathrm{ng} / \mathrm{mL}$ and $33.4 \pm 18.0 \mathrm{pmol} / \mathrm{L}$ respectively (Table 1).

\begin{tabular}{ll}
\multicolumn{2}{c}{ Table 1. Demographics of participants } \\
\hline \multicolumn{1}{c}{ Variable } & \multicolumn{1}{c}{ Results } \\
\hline Age (years) & $15.9 \pm 1.39$ \\
Gender* & \\
$\quad$ Male & $134(37.1)$ \\
$\quad$ Female & $227(62.9)$ \\
Weight $(\mathrm{kg})^{\#}$ & $53.0 \pm 16.8$ \\
Height $(\mathrm{cm})^{\#}$ & $156.2 \pm 19.2$ \\
Vitamin D $(\mathrm{ng} / \mathrm{mL})^{\#}$ & $19.6 \pm 8.2$ \\
i-PTH $(\mathrm{pmol} / \mathrm{L})^{\#}$ & $33.4 \pm 18.0$ \\
Race* & \\
$\quad$ Malay & $307(85)$ \\
$\quad$ Chinese & $54(15)$ \\
BMI* & \\
$\quad$ Obese & $27(7.5)$ \\
Normal & $292(80.9)$ \\
$\quad$ Underweight & $40(11.1)$ \\
\hline${ }^{*} \mathrm{n}(\%)$ & \\
$\#$ mean $\pm S D$ & \\
\end{tabular}

Significant factors associated with vitamin D deficiency after univariate analysis were older age, crude OR (95\% CI); 0.87 (0.72, 1.06), female gender; 22.1 (5.30, 92.3), Malay; $3.79(1.14,12.59)$, family income <RM 2000; $4.32(1.12,16.59)$ and obesity; $2.74(1.16,6.49)$ (Table 2$)$.

However, multivariate analysis revealed only Chinese race; adjusted OR (95\% CI); $0.24(0.07,0.84)$ and female gender; 23.7 (5.64, 100.3) were significant prognostic factors for hypovitaminosis D (Table 3).

\section{DISCUSSION}

The prevalence of healthy adolescents with vitamin D deficiency in Kota Bharu, Kelantan was $16.3 \%$ if it is based on the paediatric cut off $<30 \mathrm{nmol} / \mathrm{L}$. In MyHeARTs 


\begin{tabular}{|c|c|c|}
\hline Variable & Crude OR $(95 \% \mathrm{Cl})$ & $P$ value* \\
\hline Age & $0.87(0.72,1.06)$ & 0.191 \\
\hline $\begin{array}{l}\text { Gender } \\
\text { Male } \\
\text { Female }\end{array}$ & $\begin{array}{l}1.00 \\
22.1(5.30,92.3)\end{array}$ & 0.0001 \\
\hline $\begin{array}{l}\text { Race } \\
\text { Chinese } \\
\text { Malay }\end{array}$ & $\begin{array}{l}1.00 \\
3.79(1.14,12.59)\end{array}$ & 0.029 \\
\hline $\begin{array}{c}\text { Socio-economy } \\
\text { <RM } 2000 \\
\text { >RM } 2000\end{array}$ & $\begin{array}{l}1.00 \\
4.32(1.12,16.59)\end{array}$ & 0.033 \\
\hline $\begin{array}{l}\text { BMI } \\
\quad \text { Normal } \\
\text { Obesity } \\
\text { Underweight }\end{array}$ & $\begin{array}{l}1.00 \\
2.74(1.16,6.49) \\
0.61(020,1.79)\end{array}$ & $\begin{array}{l}0.022 \\
0.37\end{array}$ \\
\hline i-PTH & $1.00(0.99,1.02)$ & 0.249 \\
\hline
\end{tabular}

Table 3. Multivariate analysis for factors associated with vitamin $\mathrm{D}$ deficiency

\begin{tabular}{|c|c|c|c|c|}
\hline Variable & $\begin{array}{l}\text { Crude OR } \\
(95 \% \mathrm{CI})\end{array}$ & $\begin{array}{l}\text { Adjusted OR } \\
\quad(95 \% \mathrm{Cl})\end{array}$ & $\begin{array}{l}\text { Wald } \\
\text { statistic } \\
\text { (df) }\end{array}$ & $P$ value ${ }^{b}$ \\
\hline \multicolumn{5}{|l|}{ Race } \\
\hline Malay & 1.00 & & & \\
\hline Chinese & $0.26(0.07,0.87)$ & $0.24(0.07,0.84)$ & $4.99(1)$ & 0.025 \\
\hline \multicolumn{5}{|l|}{ Gender } \\
\hline & 1.00 & & & \\
\hline Female & $22.1(5.30,92.3)$ & $23.7(5.64,100.3)$ & $18.6(1)$ & 0.0001 \\
\hline \multicolumn{5}{|c|}{ 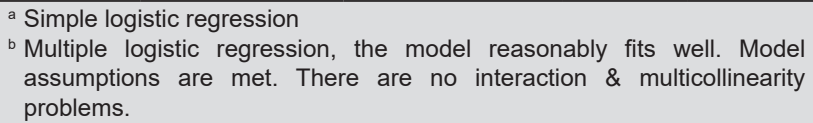 } \\
\hline \multicolumn{5}{|c|}{ Variance Inflation Factor $<10$} \\
\hline \multicolumn{5}{|c|}{ Correlation is weak that indicates no multicollinearity } \\
\hline \multicolumn{5}{|c|}{$\begin{array}{l}\text { Hosmer-Lemeshow goodness-of-fit } p \text {-value }=0.966 \text {, not significant and } \\
\text { therefore the model fits }\end{array}$} \\
\hline \multicolumn{5}{|c|}{ Overall correct classification $=83.8 \%$} \\
\hline \multicolumn{5}{|c|}{ Area under the curve $=0.762(95 \% \mathrm{Cl}=0.706,0.818)$} \\
\hline
\end{tabular}

(Malaysian Health and Adolescents Longitudinal Research Team Study) the prevalence of vitamin D deficiency was $33 \%$ among healthy adolescents from 15 schools in Selangor, Perak and Kuala Lumpur which are located in states with higher revenue than Kelantan but the definition of vitamin $\mathrm{D}$ deficiency used was $50 \mathrm{nmol} / \mathrm{L}$ that was higher than our definition of $30 \mathrm{nmol} / \mathrm{L} .{ }^{13} \mathrm{As}$ a higher cut off value was used to define hypovitaminosis $\mathrm{D}$, therefore their prevalence rate was higher. Their prevalence might be similar to us if only a lower cut off was used to define hypovitaminosis D since higher value would result in over diagnosing vitamin $\mathrm{D}$ deficiency and furthermore the cut off of $50 \mathrm{nmol} / \mathrm{L}$ is mostly used in adult trials. This current definition was based on strong evidence supported by the increased incidence of nutritional rickets with $25(\mathrm{OH}) \mathrm{D}$ concentration $<30 \mathrm{nmol} / \mathrm{L}$ based on the latest global consensus recommendations on prevention and management of nutritional rickets. ${ }^{11} \mathrm{It}$ is also consistent with the latest recommendation by The Institute of Medicine (IOM). ${ }^{12}$ There are many studies with different cut off level to diagnose Vitamin D deficiency, insufficiency and sufficiency but with higher cut off values used would likely to overestimate the burden of vitamin $\mathrm{D}$ deficiency across all age groups and this might also lead to unnecessary treatment with vitamin D. ${ }^{35,36}$ IOM (2010) committee has based its recommendation as deficiency $<30 \mathrm{nmol} / \mathrm{L}$, insufficiency $30-50 \mathrm{nmol} / \mathrm{L}$ and sufficiency $50-75 \mathrm{nmol} / \mathrm{L}$ on the indicators of bone health as review of many literature did not suggest any additional benefit beyond the recommended levels. ${ }^{12}$ Based on inverse relationship between PTH and vitamin D, the level of vitamin $\mathrm{D}$ at which $\mathrm{PTH}$ is plateauing with increasing level of vitamin $\mathrm{D}$ is defined as the cut off for vitamin D deficiency. ${ }^{37}$ The effect of high PTH with vitamin D deficiency would result in an increase in bone resorption or skeletal effects but which level of vitamin D that is associated with other non-skeletal effects is still unknown and controversial and this might contribute to different cut-off values of vitamin D used in many other trials. ${ }^{6}$

Based on univariate analysis, significant factors associated with increased odds to have hypovitaminosis D among healthy teenagers were older age, female gender, Malay race, poor socioeconomic status and obesity; OR (95\% CI): 0.87 (0.72,1.06), 22.1 (5.30, 92.3), 3.79 (1.14, 12.59), $4.32(1.12,16.59), 2.74(1.16,6.49)$. From multivariate analysis, there were only two significant predictors for hypovitaminosis $\mathrm{D}$ which were female gender and race. We found that female gender had 22.1 times increased odds than male gender to have hypovitaminosis D while Chinese had $74 \%$ reduced odds to have hypovitaminosis D compared to Malay. The risk factors associated with hypovitaminosis $\mathrm{D}$ are similar to data found in most of the other vitamin D studies. ${ }^{17-31}$ From MyHeARTs study, the factors that were identified were female gender, obesity, wearing long sleeves, Malay and Indian ethnicity. Female; 5.5 (3.4-7.5), Malay; 3.2 (1.3-8.0), Indians; 4.3 (1.6-12.0) and wearing long sleeves; $2.4(1.1,5.4)$ were the factors associated with increased odds to have hypovitaminosis D after multivariate analysis. ${ }^{13}$ A cross sectional study of 402 healthy school children aged 7-12 years old in Kuala Lumpur found that $35.3 \%$ of the children had serum $25(\mathrm{OH}) \mathrm{D}<37.5 \mathrm{nmol} / \mathrm{L}$. The subjects were younger and it was found that the high prevalence was higher in obese boys with chi square $=5.958 ; p=0.016$. As expected when a higher value for cut off was chosen, the prevalence would be higher. ${ }^{38}$ Compared to other South East Asia countries from SEANUTS survey conducted in 2010/2011 in Indonesia, Malaysia, Thailand and Vietnam, the prevalence of vitamin $\mathrm{D}$ deficiency among children with age range 0.5 12 years old were $4.1 \%$ in Malaysia, $2 \%$ in Thailand, and $11.1 \%$ in Vietnam. The subjects were younger than our cohort and the cut off value to define vitamin D deficiency was similar to our definition. Our prevalence is higher most probably since our subjects are older. Older age/ adolescents have higher metabolic demands for vitamin D, owing to the rapid growth of the skeleton during puberty and are therefore at higher risk of vitamin D deficiency. ${ }^{39}$ Among risk factors associated with vitamin D deficiency from SEANUTS were older age, girls, wearing head scarf or long trousers and darker skins in certain ethnicity especially Indian. In Malaysia (SEANUTS), significant differences were noted between races in which Indians had lower value of vitamin $\mathrm{D} ; 45.6 \pm 2.9$ ) compared to Malays; $53.7 \pm 1.2$, and Chinese; $56.2 \pm 1.7 \mathrm{nmol} / \mathrm{L}$. Older age; $1.4(1.2$ $1.5)$, female gender; $1.8(1.0,3.1)$ had increased odds to have hypovitaminosis D. In Thailand (SEANUTS), older age; $1.1(1.0,1,2)$ female gender; $2 \cdot 2(1.3,3.7)$ were associated with increased odds of hypovitaminosis D. In Vietnam (SEANUTS), significant factors that were associated with increased odds for hypovitaminosis D were older age; 1.1 $(0.9,14)$ and female gender $1.0(06,1.7)$ and the same were also seen in Indonesia (SEANUTS), with values for older age at $1.1(1.0,1.2)$ and for female gender at $2.7(1.3,5.5) .{ }^{40}$ 
Solar radiation (UVB band of 290-315 nm) stimulates synthesis of pre-vitamin $D$ in the skin from 7-dehydrocholesterol to cholecalciferol, an inactive metabolite of vitamin D. ${ }^{32}$ The sun exposure is affected by many factors such as latitude, altitude, season, time of the day, cloud cover, air quality and personal factors which are life style, clothing, time spent outdoor and use of sunscreen. The dose-response of circulating $25(\mathrm{OH}) \mathrm{D}$ to cutaneous UVB exposure is dependent on skin pigmentation, age, body composition, genetic factors and baseline $25(\mathrm{OH}) \mathrm{D} \cdot{ }^{17}$

Kota Bharu is the capital of Kelantan and it is located at $6.133 \mathrm{~N}$ 102.23 E. Abundant sunlight is received throughout the year as Malaysia is located close to the equator. Most of the Malays have darker skin compared to Chinese and this contributed to higher proportion of Malay teenagers with vitamin D deficiency since sunlight is the main source of endogenous vitamin $\mathrm{D}$ synthesis. The mean vitamin D (Malay vs Chinese) was 19.0 vs $23.0 \mathrm{ng} / \mathrm{mL}$; $(p=0.001)$. Males have higher level of vitamin D compared to females; 25.4 vs $16.2 \mathrm{ng} / \mathrm{mL}$. Males were significantly taller and heavier compared to females; $(162.1$ vs $152.8 \mathrm{~cm}$ : $p=0.006)$, (56.1 vs $51.1 \mathrm{~kg}$ : $p<0.001)$. Majority of the subjects had normal BMI; 292 (80.9\%) and the proportion of obesity was only $7.5 \%$. Individuals with obesity are often vitamin $\mathrm{D}$ deficient as vitamin $\mathrm{D}$ is trapped in adipose tissue potentially because of insufficient lipolytic stimulation and tissue dysfunction/adaptation resulting from adipose expansion. ${ }^{41}$ As males were significantly heavier and taller compared to females with normal BMI, this implies higher lean mass than fat mass and therefore higher level of vitamin D compared to female. Other possible associations for a difference in the level of vitamin D between genders are the extent of clothing/head cover and time spent outdoor which were not analysed in this study.

In general, higher rate of obesity and increasing BMI in females are some of the known reasons for lower vitamin D levels in females. ${ }^{42,43}$ Obesity is associated with hypovitaminosis D for some other reasons too. Most of them have less outdoor activity and therefore less sun exposure There is alteration in the vitamin $\mathrm{D}$ feedback mechanism with higher production of $1,25(\mathrm{OH}) 2 \mathrm{D}$, that exerts negative feedback control on the hepatic synthesis of serum $25(\mathrm{OH}) \mathrm{D}$. There is also a change in the metabolic clearance due to enhanced uptake by adipose tissue and decreased bioavailability of vitamin D from cutaneous and dietary sources because of its deposition in body fat compartment. ${ }^{42,43}$

Our study has a few limitations such as limited detailed surveys on diet and other personal/lifestyle factors. The inclusion of dietary survey will be useful since most often the food intake is deficient in vitamin D content. Exploring other lifestyle/personal factors such as time spent in outdoors, clothing, use of sunscreen are some of the important clues that may explain the underlying reasons for vitamin $\mathrm{D}$ deficiency. There was some selection bias in terms of number of females compared to males; (227 vs 134) most likely related to convenient sampling and races; Malay vs Chinese; (307 vs 54) since Kelantan has predominantly Malay ethnicity. Initially a total of 367 were recruited but 7 had to be excluded due to missing blood results associated with insufficient blood volume (3) and inadequate number of other races; Indian (2) and Siamese (1).

\section{CONCLUSION}

The prevalence of hypovitaminosis D among healthy adolescents in Kota Bharu, Kelantan was $16.9 \%$ based on the most recent cut off value of $30 \mathrm{nmol} / \mathrm{L}$. Female gender and Malay race were the significant risk factors associated with hypovitaminosis D. Higher cut off limit used to diagnose vitamin D deficiency would result in overestimation of the prevalence rate.

\section{Statement of Authorship}

Both authors certified fulfillment of ICMJE authorship criteria.

\section{Author Disclosure}

Both authors declared no conflict of interest.

\section{Funding Source}

The University Science Malaysia provided short term grant funding for the study with reference number 304/PPSP/613-10055.

\section{References}

1. Munns CF, Simm PJ, Rodda CP, et al. Incidence of vitamin D deficiency rickets among Australian children: An Australian Paediatric Surveillance Unit study. Med J Aust. 2012; 196(7):466-8. PMID: 22509879. https://doi.org/10.5694/mja11.10662.

2. Dawodu A, Agarwal M, Sankarankutty M, Hardy D, Kochiyil J, Badrinath P. Higher prevalence of vitamin D deficiency in mothers of rachitic than nonrachitic children. J Paediatr. 2005;147(1):109-11. PMID: 16027707. https://doi.org/10.1016/j.jpeds.2005.03.001.

3. Specker BL, Ho ML, Oestreich A, et al. Prospective study of vitamin D supplementation and rickets in China. J Pediatr. 1992;120(5):733-9. PMID: 1578308. https://doi.org/10.1016/s0022-3476(05)80236-7.

4. Ward LM, Gaboury I, Ladhani M, Zlotkin S. Vitamin D-deficiency rickets among children in Canada. Can Med Assoc J. 2007;177(2): 161-6. PMID: 17600035.PMCID: PMC1913133. https://doi.org/10.1503/ cmaj.061377.

5. Pike JW, Goozé LL, Haussler MR. Biochemical evidence for 1,25-dihydroxyvitamin D receptor macromolecules in parathyroid, pancreatic, pituitary, and placental tissues. Life Sci. 1980; 26(5):407-14 https://doi.org/10.1016/0024-3205(80)90158-7.

6. Mithal A, Wahl DA, Bonjour JP, et al. Global vitamin D status and determinants of hypovitaminosis D status. Osteoporosis Int. 2009;20(11):1807-20. PMID: 19543765. https://doi.org/10.1007/s00198009-0954-6.

7. Colston K, Hirt M, Feldman D. Organ distribution of the cytoplasmic 1,25-dihydroxycholecalciferol receptor in various mouse tissues. Endocrinology. 1980;107(6):1916-22. PMID: 6253281. https://doi.org/ 10.1210/endo-107-6-1916.

8. Marwaha RK, Tandon N, Reddy DR, et al. Vitamin D and bone mineral density status of healthy schoolchildren in northern India. Am J Clin Nutr 2005;82(2):477-82. PMID: 16087996. https://doi.org/10.1093/ ajcn.82.2.477.

9. Angurana SK, Angurana RS, Mahajan G, Kumar N, Mahajan V. Prevalence of vitamin D deficiency in apparently healthy children in north India. J Pediatr Endocrinol Metab 2014; 27(11-12):1151-6. PMID: 25006749. https://doi.org/10.1515/jpem-2013-0387.

10. Ritu G, Gupta A. Vitamin D deficiency in India: Prevalence, causalities and interventions. Nutrients. 2014;6(2):729-75. PMID: 24566435 PMCID: PMC3942730. https://doi.org/10.3390/nu6020729.

11. Munns C, Shaw N, Kiely M, et al. Global consensus recommendations on prevention and management of nutritional rickets. J Clinical Endocrinol Metab. 2016;101(2):394-415. PMID: 26745253. PMCID: PMC4880117. https://doi.org/10.1210/jc.2015-2175.

12. Ross AC, Manson JE, Abrams SA, et al. The 2011 report on dietary reference intakes for calcium and vitamin D from the Institute of Medicine: What clinicians need to know. J Clin Endocrinol Metab. 2011;96(1):53-8. PMID: 21118827. PMCID: PMC3046611. https://doi. org/10.1210/jc.2010-2704.

13. Al-Sadat N, Majid HA, Sim PY, et al. Vitamin D deficiency in Malaysian adolescents aged thirteen years: Findings from the Malaysian Health and Adolescents Longitudinal Research Team study (MyHeARTs). BMJ Open. 2016;18(6):e010689. PMID: 27540095 PMCID: PMC5013370. https://doi.org/10.1136/bmjopen-2015-010689.

14. Holick MF, Schnoes HK, DeLuca HF. Identification of 1,25-dihydroxycholecalciferol, a form of vitamin D3 metabolically active in the intestine. Proc Natl Acad Sci U S A. 1971;68(4):803-4. PMID: 4323790. PMCID: PMC389047. https://doi.org/10.1073/pnas.68.4.803.

15. Holick MF, Schnoes HK, DeLuca HF, Suda T, Cousins RJ. Isolation and identification of 1,25-dihydroxycholecalciferol. A metabolite of 
vitamin D active in intestine. Biochemistry. 1971;10(14):2799-804. PMID: 4326883. https://doi.org/10.1021/bi00790a023.

16. Jones G, Strugnell SA, DeLuca HF. Current understanding of the molecular actions of vitamin D. Physiol Rev. 1998;78(4):1193-231 PMID: 9790574. https://doi.org/10.1152/physrev.1998.78.4.1193.

17. Webb AR, Kline L, Holick MF. Influence of season and latitude on the cutaneous synthesis of vitamin D3: Exposure to winter sunlight in Boston and Edmonton will not promote vitamin D3 synthesis in human skin. J Clin Endocrinol Metab. 1988;67(2):373-8. PMID: 2839537. https://doi.org/10.1210/jcem-67-2-373.

18. Agarwal KS, Mughal MZ, Upadhyay P, Berry JL, Mawer EB, Puliyel JM. The impact of atmospheric pollution on vitamin $D$ status of infants and toddlers in Delhi, India. Arch Dis Child. 2002; 87(2):111-3. PMID: 12138058. PMCID: PMC1719192. https://doi.org/10.1136/adc.87.2.111.

19. Harris SS, Dawson-Hughes B. Seasonal changes in plasma 25-hydroxyvitamn D concentrations of young American black and white women. Am J Clin Nutr. 1998;67(6):1232-6. PMID: 9625098. https://doi.org/10.1093/ajcn/67.6.1232.

20. Petersen B, Wulf HC, Triguero-Mas M, et al. Sun and ski holidays improve vitamin D status, but are associated with high levels of DNA damage. J Invest Dermatol. 2014; 134(11):2806-13. PMID: 24844860. https://doi.org/10.1038/iid.2014.223.

21. Richter K, Breitner S, Webb A, et al. Influence of external, intrinsic and individual behaviour variables on serum $25(\mathrm{OH}) \mathrm{D}$ in a German survey. J Photochem Photobiol B. 2014; 140C:120-9. PMID: 25116947. https://doi.org/10.1016/j.jphotobiol.2014.07.018.

22. Terushkin V, Bender A, Psaty EL, Engelsen O, Wang SQ, Halpern AC. Estimated equivalency of Vitamin D production from natural sun exposure versus oral vitamin D supplementation across Seasons at two US latitudes. J Am Acad Dermatol. 2010; 62(6):929.e1-9. PMID: 20363523. https://doi.org/10.1016/j.jaad.2009.07.028.

23. Holick MF. McCollum Award Lecture, 1994: Vitamin D-new horizons for the 21th century. Am J Clin Nutr. 1994;60(4):619-30. PMID: 8092101. https://doi.org/10.1093/ajcn/60.4.619

24. Bodekær M, Petersen B, Thieden E, et al. UVR exposure and vitamin $\mathrm{D}$ in a rural population. A study of outdoor working farmers, their spouses and children. Photochem Photobiol Sci. 2014; 13(11):15981606. https://doi.org/10.1039/C4PP00188E.

25. Kift R, Berry JL, Vail A, Durkin MT, Rhodes LE, Webb AR. Lifestyle factors including less cutaneous sun exposure contribute to starkly lower vitamin D levels in U.K. South Asians compared with the white population. Br J Dermatol. 2013;169(6):1272-8. PMID: 23855783. https://doi.org/10.1111/bjd.12518.

26. Thieden E, Philipsen PA, Heydenreich J, Wulf $\mathrm{CH}$. UV radiation exposure related to age, sex, occupation, and sun behavior based on time-stamped personal dosimeter readings. Arch Derm. 2004;140(2): 197-203. PMID: 14967793. https://doi.org/10.1001/archderm.140.2.197.

27. Diffy BL. Is casual exposure to summer sunlight effective at maintaining adequate vitamin D status? Photodermatol Photoimmunol Photomed. 2010;26(4):172-6. PMID: 20626818. https://doi.org/10.1111/ j.1600-0781.2010.00518.x.

28. Farrar MD, Kift R, Felton SJ, et al. Recommended summer sunlight exposure amounts fail to produce sufficient vitamin D status in UK adults of South Asian origin. Am J Clin Nutr. 2011; 94(5):1219-24. PMID: 21918215. https://doi.org/10.3945/ajcn.111.019976.
29. Farrar MD, Webb AR, Kift R, et al. Efficacy of a dose range of simulated sunlight exposures in raising vitamin D status in South Asian adults: Implications for targeted guidance on sun exposure. Am J Clin Nutr. 2013;97(6):1210-6. PMID: 23615828. https://doi.org/10.3945/ ajcn.112.052639.

30. MacLaughlin J, Holick MF. Aging decreases the capacity of human skin to produce vitamin D3. J Clin Invest. 1985;76(4):1536-8. PMID: 2997282. PMCID: PMC424123. https://doi.org/10.1172/JCI112134.

31. Webb AR, Kift R, Durkin MT, et al. The role of sunlight exposure in determining the vitamin $\mathrm{D}$ status of the U.K. white adult population. Br J Dermatol. 2010;163(5):1050-5. PMID: 20716215. https://doi. org $/ 10.1111 /$ j.1365-2133.2010.09975.x

32. Holick MF. Environmental factors that influence the cutaneous production of vitamin D. Am J Clin Nutr. 1995;61(3 Suppl):638S-645S PMID: 7879731. https://doi.org/10.1093/ajcn/61.3.638S.

33. Wagner CL, Greer FR, American Academy of Pediatrics Section on Breastfeeding, American Academy of Pediatrics Committee on Nutrition. Prevention of rickets and vitamin D deficiency in infants, children, and adolescents. Pediatrics. 2008;122(5):1142-52. PMID: 18977996. https://doi.org/10.1542/peds.2008-1862

34. Theintz G, Buchs B, Rizzoli R, et al. Longitudinal monitoring of bone mass accumulation in healthy adolescents: Evidence for a marked reduction after 16 years of age at the levels of lumbar spine and femoral neck in female subjects. J Clin Endocrinol Metab. 1992;75(4): 1060-5. PMID: 1400871. https://doi.org/10.1210/jcem.75.4.1400871.

35. Ladhani S, Srinivasan L, Buchanan C, Allgrove J. Presentation of vitamin D deficiency. Arch Dis Child. 2004;89(8):781-4. PMID: 15269083. PMCID: PMC1720051. https://doi.org/10.1136/adc.2003.031385.

36. Lulseged S. Severe rickets in a children's hospital in Addis Ababa. Ethiop Med J. 1990; 28(4):175-81. PMID: 2249677.

37. Thacher TD, Clark BL. Vitamin D insufficiency. Mayo Clin Proc. 2011; 86(1):50-60. PMID: 21193656. PMCID: PMC3012634. https://doi. org/10.4065/mcp.2010.0567" https://doi.org/10.4065/mcp.2010.0567.

38. Khor GL, Chee WSS, Shariff ZM, et al. High prevalence of vitamin $\mathrm{D}$ insufficiency and its association with BMI-for-age among primary school children in Kuala Lumpur, Malaysia. BMC Public Health. 2011;11:95. PMID: 21310082. PMCID: PMC3045951. https://doi. org/10.1186/1471-2458-11-95.

39. Pérez-López FR, Pérez-Roncero G, López-Baena MT. Vitamin D and adolescent health. Adolesc Health Med Ther.2010; 1-8. PMID: 28028383. PMCID: PMC5175574. https://doi.org/10.2147/AHMT.S7472

40. Poh BK, Rojroongwasinkul N, Nguyen BKL, et al. 25-hydroxy-vitamin D demography and the risk of vitamin D insufficiency in the South East Asian Nutrition Surveys (SEANUTS). Asia PAC J Clin Nutr. 2016 25(3):538-48. PMID: 27440689. https://doi.org/10.6133/apjcn.092015.02.

41. Hengist A, Perkin O, Gonzalez JT, et al. Mobilizing vitamin D from adipose tissue: The potential impact of exercise. Nutr Bull. 2019;(44).2535. https://doi.org/10.1111/nbu.12369.

42. Pereira-Santos M, Costa PRF, Assis AMO, Santos CAST, Santos DB. Obesity and vitamin D deficiency: A systematic review and metaanalysis. Obes Rev. 2015;16(4):341-9. PMID: 25688659. https://doi. org10.1111/obr.12239.

43. Pourshahidi LK. Vitamin D and obesity: current perspectives and future directions. Proc Nutr Soc. 2015; 74(2):115-24. https://doi. org/10.1017/S0029665114001578

Authors are required to accomplish, sign and submit scanned copies of the JAFES Author Form consisting of: (1) Authorship Certification, that authors contributed substantially to the work, that the manuscript has been read and approved by all authors, and that the requirements for authorship have been met by each author; (2) the Author Declaration, that the article represents original material that is not being considered for publication or has not been published or accepted for publication elsewhere, that the article does not infringe or violate any copyrights or intellectual property rights, and that no references have been made to predatory/ suspected predatory journals; (3) the Author Contribution Disclosure, which lists the specific contributions of authors; and (4) the Author Publishing Agreement which retains author copyright, grants publishing and distribution rights to JAFES, and allows JAFES to apply and enforce an Attribution-Non-Commercia Creative Commons user license. Authors are also required to accomplish, sign, and submit the signed ICMJE form for Disclosure of Potential Conflicts of Interest. For original articles, authors are required to submit a scanned copy of the Ethics Review Approval of their research as well as registration in trial registries a appropriate. For manuscripts reporting data from studies involving animals, authors are required to submit a scanned copy of the Institutional Animal Care and Use Committee approval. For Case Reports or Series, and Images in Endocrinology, consent forms, are required for the publication of information about patients; otherwise, appropriate ethical clearance has been obtained from the institutional review board. Articles and any other material published in the JAFES represent the work of the author(s) and should not be construed to reflect the opinions of the Editors or the Publisher. 